\title{
CHARACTERIZATION AND MITIGATION OF ELECTRO-STATIC BONDING FAILURES IN MICROSENSORS
}

\author{
Kamaljeet Singh, A.V. Nirmal and S.V. Sharma \\ Systems Engineering Group, ISRO Satellite Centre, India
}

\begin{abstract}
Electrostatic bonding between glass and silicon is carried out in micro sensor devices to achieve higher bond strength thus eliminating the requirement of adhesives. This can also be useful in providing hermiticity and results in reliable operation of the micro sensor devices. Practically the sensor performance is prone to long term drift mainly due to process associated with the assembly and packaging. Bonding is the one of the critical process in micro sensor and generally sensor stability is dependent on this process along with other packaging material and methodology. Bond strength is one of the critical parameters to find out the quality of bond and the same is quantified and compared for different conditions. This article details electrostatic bonding process, various parameters responsible for the reliable bonding, modelling and characterization along with simple methodology to achieve higher bond strength.
\end{abstract}

Keywords:

Bonding, Micro-Sensor, Anodic, Electrostatic, Sensor, Bond Strength

\section{INTRODUCTION}

In MEMS technology packaging and bonding plays an important role for reliable operation of the sensors. As compared to standard IC techniques, sensor chip is directly exposed to abrasive and hostile environment so die bonding and packaging are the important parameters for providing mechanical support, thermal path, and electrical contact in microsensors [1]. Various techniques and materials are used for bonding and package sealing such as eutectic bonding, fusion bonding, epoxy bonding, polyimide bonding, ultrasonic welding, laser welding, low temperature glass bonding etc. The main criteria associated with the bonding and sealing process involves creation of stress due to differential thermal expansion along with other associated phenomena such as fatigue and creep of the bonding layer, unreliable bonds, complex and difficult assembly methods [2].

Micro-sensors such as acoustic sensor, pressure sensor, accelerometer, microfluidic devices need bonding operations before mounting in the package. Bulk micromachining process [3] associated with these sensors makes the diaphragm thin thus resulting in the fragility of the chip. To overcome the fragility and to provide hermiticity (in case of absolute pressure sensor), bonding of the sensor either with silicon or glass is carried out. The bonding processes mostly employed are: eutectic, anodic and fusion bonding. Eutectic bonding is based on the eutectic point between gold and silicon where gold is in intimate contact with silicon. Availability of the gold is ensured by coating die using sputtering or sandwiching preform in between the die and silicon substrate consisting of $80 \% \mathrm{Au}$ in the composition. The gold atoms diffuse interstitially at increasing temperature forming a thin layer at the interface. Main challenge associated with this phenomenon is the fast oxidization of the silicon wafer which prohibits the bond formation. Also this process along with other technique such as thermo compression bond technique utilizing gold is not recommended in the case of integrated sensor consisting of CMOS electronics on the same chip [1,3]. Fusion bonding is based on the high temperature $\left(\sim 1000^{\circ} \mathrm{C}\right)$ along with high force and is not suitable in case of process consisting of aluminium metallization layer [4].

Electrostatic bonding (anodic bonding) is the most suitable, reliable and superior compared to other two techniques [2]. This technique is based on the simultaneous application of potential and temperature to bond silicon to glass, silicon oxide to glass or silicon to silicon with interface layer of pyrex glass [5]. Realization of absolute pressure sensor device needs vacuum at one side of sensor membrane which is created by bonding after micromachining process. The bonding process is based on the heterogeneous material such as glass and silicon introducing thermo-mechanical stress [6].

Other constraints in realization of these devices are due to the structural limitations imposed by the traditional backside etching process resulting in poor bond strength due to availability of less and contaminated surface area for bonding. As etched wafer with thin diaphragm is prone to breakage or wash out due to chemical treatment so a simple methodology is proposed to achieve better bond strength without employing any chemical treatment. This article details the anodic bonding process, process parameters, bonding methodology and various aspects to mitigate the long term drift associated with the poor bonding.

\section{ANODIC BONDING PROCESS}

Table.1. Comparison of various bond mechanisms

\begin{tabular}{|c|c|c|c|c|}
\hline Parameters & Anodic & Fusion & Eutectic & Solder \\
\hline Bond strength & $\begin{array}{c}\text { Very } \\
\text { strong }\end{array}$ & Excellent & Strong & Strong \\
\hline Hermiticity & Good & Excellent & Excellent & Excellent \\
\hline $\begin{array}{c}\text { Temperature } \\
\left({ }^{\circ} \mathrm{C}\right)\end{array}$ & $250-400$ & $200-1000$ & $>363$ & $57-400$ \\
\hline TCE mismatch & OK & Good & OK & Poor \\
\hline $\begin{array}{c}\text { CMOS } \\
\text { compatibility }\end{array}$ & OK & Poor & OK & Good \\
\hline $\begin{array}{c}\text { Planarization } \\
\text { capability }\end{array}$ & Poor & Very Poor & Good & Good \\
\hline
\end{tabular}

Anodic bonding is the field assisted glass-silicon sealing involving that bonds materials to silicon at high temperature under an applied voltage. Metals and glasses form permanent bond under these circumstances. Si-Si anodic bonding can also be carried out by having pyrex interfacial layer in between either 
using preform or by depositing it using RF sputtering on the die. Table. 1 shows comparison between various topologies.

Present article deals with the bonding of silicon and glass whereas cathode is attached to glass and silicon wafer is attached to anode via hot plate in vacuum at elevated temperature of $400^{\circ} \mathrm{C}$ as shown in Fig.1. Alternatively keeping glass on the chuck and silicon on top results in the poor bond formation as in this process simultaneous bond formation takes place resulting in trapped voids.

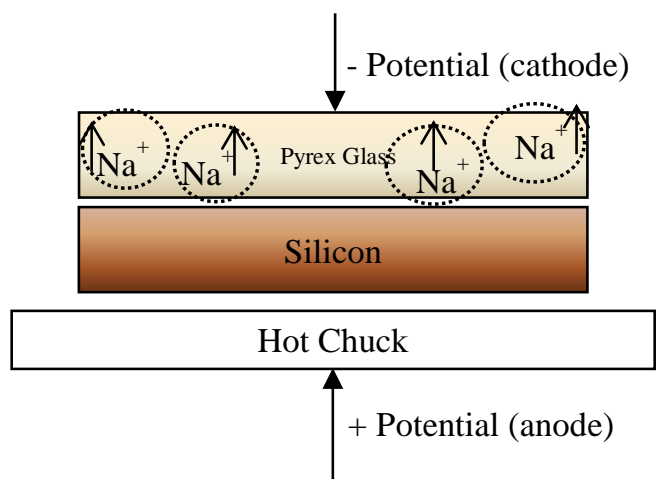

Fig.1. Generic set-up

Positive terminal is connected to the silicon wafer and the negative terminal is connected to the Pyrex glass wafer and due to application of electric field of several hundred to a thousand volts the glass seals to the silicon wafer with the formation of covalent bond. The bonded areas initially appear as dark splotches starting in the area and slowly spread out. This phenomenon is associated with the ionic movement primarily due to the presence of mobile sodium ions in the Pyrex 7740 glass.

Table.2. Silicon and Pyrex 7740 characteristics at various temperatures

\begin{tabular}{|c|c|c|}
\hline $\begin{array}{c}\text { Temperature } \\
\left({ }^{\circ} \mathbf{C}\right)\end{array}$ & $\begin{array}{c}\text { Silicon TCE } \\
\left(\mathbf{p p m}^{\circ}{ }^{\circ} \mathbf{C}\right)\end{array}$ & $\begin{array}{c}\text { Glass TCE } \\
\left(\mathbf{p p m}^{\boldsymbol{}}{ }^{\mathbf{C}} \mathbf{C}\right)\end{array}$ \\
\hline 300 & 3.78 & 3.3 \\
\hline 350 & 3.86 & 3.32 \\
\hline 400 & 3.96 & 3.40 \\
\hline 450 & 4.02 & 3.60 \\
\hline
\end{tabular}

In comparison of Borosilicate, Soda lime, Hoya, Pyrex 7070, SOG technique and other similar materials, Pyrex 7740 is preferred as it is having better thermal conductivity, higher thermal shock resistance along with close match of thermal coefficients of expansion with silicon (Table.2) resulting in less generation of less residual stress. Overall variation of the pyrex glass with temperature is in the range of -100 to $100 \mathrm{ppm}$.

Elevated temperature along with high potential accelerates the mobility of the positive sodium ions towards the anode and thus form space charge region in the pyrex glass. The overall structure can be modelled as combination of variable parallel plate capacitor (depletion region) in series with variable resistor (glass wafer) as shown in Fig.2.

Initially the current density increases indicating the formation of depletion region afterwards the contribution of ionic conductivity associated with glass wafer becomes negligible. This results in the high contact electrostatic force of around 350 psi between the interface regions.

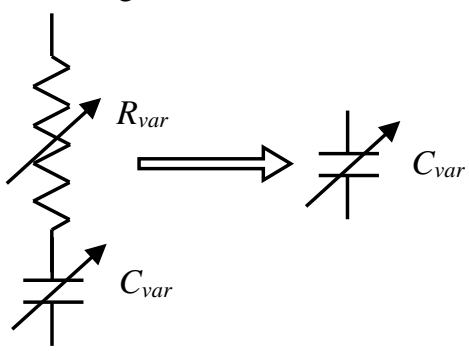

Fig.2. Equivalent model of the bonded assembly (a) initial (b) after bond formation

As pyrex glass constituent comprises of $\mathrm{Na}, \mathrm{B}, \mathrm{Al}$ atoms so mathematically this process can be shown as:

$$
\begin{aligned}
{\left[\mathrm{AlO}_{4}\right] \mathrm{Na}+\mathrm{H}^{+} } & \leftrightarrow\left[\mathrm{AlO}_{4}\right] \mathrm{H}+\mathrm{Na}^{+} \\
{\left[\mathrm{BO}_{4}\right] \mathrm{Na}+\mathrm{H}^{+} } & \leftrightarrow\left[\mathrm{BO}_{4}\right] \mathrm{H}+\mathrm{Na}^{+} \\
\mathrm{Si}+4[\mathrm{OH}]^{-} & \rightarrow \mathrm{Si}(\mathrm{OH})_{4}+4 \mathrm{e}^{-} \\
\mathrm{Si}(\mathrm{OH})_{4} & \rightarrow \mathrm{SiO}_{2}+2 \mathrm{H}_{2} \mathrm{O}
\end{aligned}
$$

\begin{tabular}{|c|c|}
\hline Process Parameters & Process Requirements \\
\hline $\begin{array}{l}\text { Electric potential } \\
(\sim 1000-1200 \mathrm{~V})\end{array}$ & $\begin{array}{l}\text { Glass wafer } \\
(\sim 20 \text { mils })\end{array}$ \\
\hline $\begin{array}{l}\text { Chuck Temperature } \\
\left(\sim 400^{\circ} \mathrm{C}\right)\end{array}$ & $\begin{array}{c}\text { Electrode material } \\
\text { (Graphite) }\end{array}$ \\
\hline $\begin{array}{l}\text { Current Density } \\
\qquad\left(1 \mathrm{~A} / \mathrm{m}^{2}\right)\end{array}$ & $\begin{array}{l}\text { Surface roughness } \\
(<1 \mathrm{um})\end{array}$ \\
\hline Atmosphere $\left(\sim 1 \mathrm{e}^{5}\right.$ bar $)$ & $\mathrm{SiO}_{2}$ thickness $\left(<2000 A^{\circ}\right)$ \\
\hline $\begin{array}{c}\text { Process time } \\
(30-60 \text { min after stabilization })\end{array}$ & $\begin{array}{c}\Delta \text { TCE between } \mathrm{Si} \text { and Glass } \\
(\mathrm{min})\end{array}$ \\
\hline
\end{tabular}

The Table. 3 summarizes the process parameters and process requirements of the bonding process.

Table.3. Process criteria for bonding operations

As shown in Table.3, process requirements decide the typical value of various parameters. Rough surfaces increase the requirement of high temperature but aluminium metallization restricts operations below $450^{\circ} \mathrm{C}$. Also at temperature greater than $300^{\circ} \mathrm{C}$, the thermal expansion coefficient between glass and silicon starts deviating and introduces higher stress. Electric potential value is dependent on the glass thickness as lower glass thickness needs lesser potential. Overall process time is the function of temperature and available bonded area which can be optimized accordingly (Table.4).

Table.4. Effect of process parameters

\begin{tabular}{|c|c|c|}
\hline Process Time & Temperature & Pressure \\
\hline$\uparrow($ Bonding) & $\downarrow$ & - \\
\hline$\uparrow($ Bonding) & - & $\downarrow$ \\
\hline$\uparrow$ (Ring width/Newton fringes) & $\downarrow$ & - \\
\hline$\downarrow$ (Ring width/Newton fringes) & - & $\downarrow$ \\
\hline
\end{tabular}


Atmosphere can vary according to the application and in case of absolute pressure sensor, bonding is carried out in higher vacuum levels resulting in longer time duration as wafer temperature becomes lower than the set temperature due to elimination of convection mode of heat transfer.

Chuck electrode also plays pivotal role as contamination or ions on the chucks restricts the proper bond formation and resistance measurement at different points of the chuck is recommended before operations.

\section{FLOW CHART AND METHODOLOGY}

Standard process flow of bonding is shown in Fig. 3 for the standard and SOI wafer.

Various layers for protection such as oxide and nitride stack is to be removed before carrying out bonding operations and wafer needs to be thoroughly cleaned. The basic advantage of SOI wafer is precise control of diaphragm thickness. Bonding of micro-machined sensor is critical as bonding is carried out after post processing which needs to be taken into account various factors such as-less area availability due to silicon consumption, decrease in surface quality hindering surface activation, handling of wafer due to wet etching, proper drying and cleaning mechanism to remove contamination. As less area can be overcome by reducing the die availability in the wafer whereas cleaning methodology imposes challenge as chemical treatment

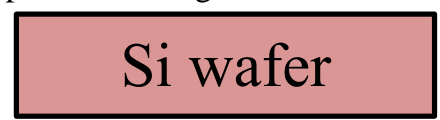

can damage the front end of the wafer. The alternative methodology adopted is the short time oxygen plasma activation along with DI water treatment to ensure a hydrophilic surface with free radicals availability. This leads to less bonding voids and surface defects. Before carrying out the bonding process various steps to be carried out to ensure the cleanliness of the wafers. Unprocessed wafer to be bonded can be cleaned using RCA $\left(\mathrm{NH}_{4} \mathrm{OH}+\mathrm{H}_{2} \mathrm{O}_{2}+\mathrm{H}_{2} \mathrm{O}\right)$ while chemical treatment on process wafer is avoided as front side needs extensive protection such as using vacuum zig holder. The holder process is not fool proof as slight chemical slippage renders the wafer unusable. In present case, ultrasonic cleaning is carried out on processed silicon and polished glass wafer using DI water. Quality of the bond is ensured by performing visual inspection and destructive tests. Clear glass wafer is indicative of the fully bond process whereas darker areas with Newton fringes or circles is indicative of the unbounded areas. After the completion of the bond process, the bonded wafers are dipped in DI water for some time followed by separation of the dies with blades. Easier separation, water seepage are indication of poor bonding whereas fracture of silicon with blade operation indicates strong bond. Reliable bond strength can be quantified by carrying out die shear test. The test is carried out after placing the bonded die on the PCB with the epoxy. Separation of the complete die indicates strong bond in comparison to the sticking or breaking of the glass indicating poor bond strength [7].

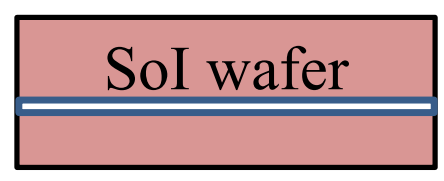

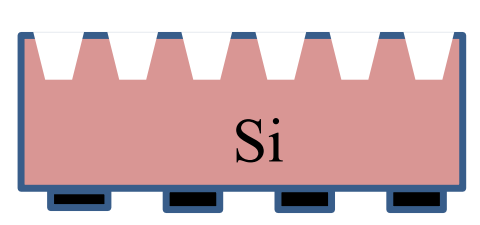

$\mathrm{KoH}$

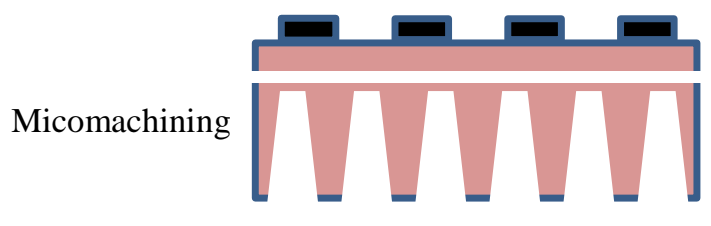

$\mathrm{KoH} \& \mathrm{BOE} \operatorname{dip}$
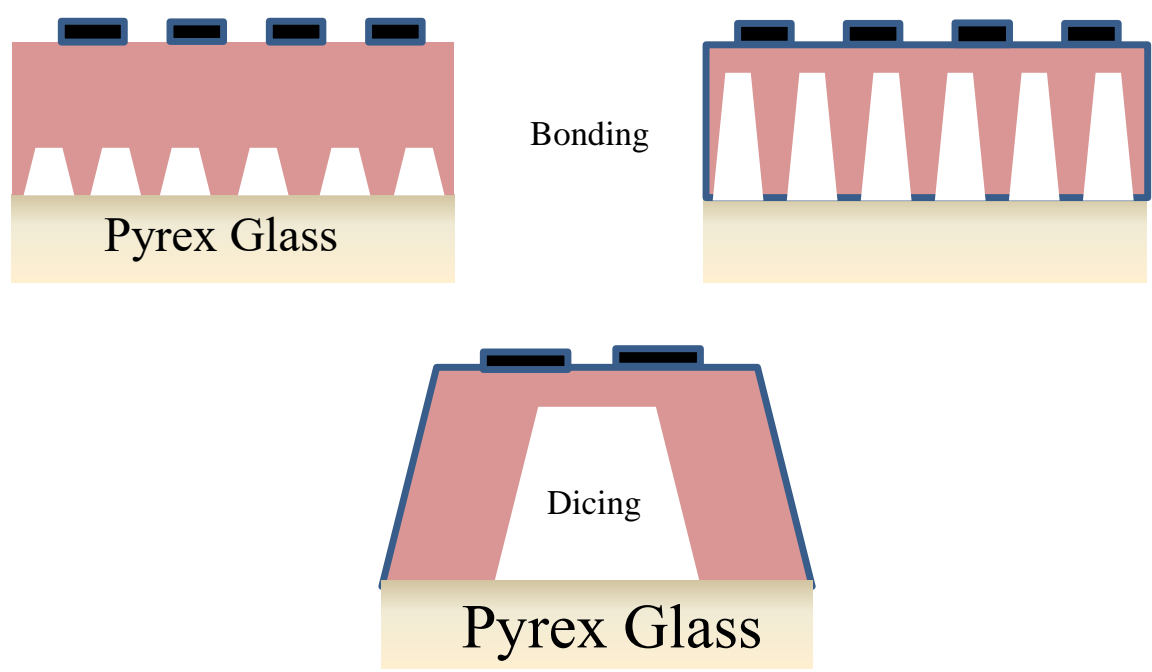

Fig.3. Bonding process flow in case of standard and SOI wafer 


\section{EXPERIMENTAL RESULTS}

Various methodologies exist to validate the bond quality. Non-destructive techniques such as optical inspection, continuous dipping in water, fine and gross leak tests can be carried out but will not be conclusive. Alternatively, TEM, crack and die shear tests can be carried out to find out the bond strength. The bonds is characterized by its strength covering shear and pull strength along with hermiticity. In present study, bond strength characterization is carried out at multiple places by carrying out the die-shear test (bond pull tester) using MIL-STD-883. The characterization is carried out for the bonded die having glass thickness of $\sim 500 \mu \mathrm{m}$. Standard wafers are taken for bonding and two different cleaning methodologies are employed before bonding operations as shown in Table.5.

Table.5. Bond strength characterization with different cleaning methodology

\begin{tabular}{|c|c|}
\hline $\begin{array}{c}\text { Bond Strength( } \sim \text { Kgf }) \\
\text { DI cleaned } \\
\left(\mathbf{1}^{\text {st }} \text { Method }\right)\end{array}$ & $\begin{array}{c}\text { Bond Strength( } \sim \text { Kgf }) \\
\text { DI \&UV treated wafer } \\
\left.\mathbf{( 2}^{\text {nd }} \text { Method }\right)\end{array}$ \\
\hline 15.00 & 36.50 \\
\hline 17.60 & 31.20 \\
\hline 21.80 & 25.00 \\
\hline 21.50 & 10.90 \\
\hline 6.50 & 35.00 \\
\hline
\end{tabular}

Above table shows that de-ionized (DI) cleaning wafers yields poor bond strength as compared to heated $\left(50^{\circ} \mathrm{C}\right)$ DI cleaning along with UV treatment $(34 \mathrm{KHz})$. This validates the methodology showing that bond strength drastically increases at the weakest bond points. The hot DI water along with UV treatment results in the surface activation of the species and ensuring availability of oxygen and hydrogen at the bond surface. Also UV cleaning removes contamination and water molecules diffuses into the glass increasing sodium atom's mobility. This results in formation of high quality bond due to faster $\mathrm{SiO}_{2}$ formation at the interface and fast ionic movement as shown in Eq.(1).

Table.6. Bond strength comparison of cavity wafer

\begin{tabular}{|c|c|c|}
\hline $\begin{array}{c}\text { Bond strength } \\
(\sim \text { Kgf }) \\
\text { Plain wafer }\end{array}$ & $\begin{array}{c}\text { Bond } \\
\text { strength( } \sim \text { Kgf }) \\
\text { Cavity std wafer }\end{array}$ & $\begin{array}{c}\text { Bond } \\
\text { strength( } \sim \text { Kgf }) \\
\text { Cavity SOI wafer }\end{array}$ \\
\hline 34.00 & 21.20 & 12.70 \\
\hline 37.50 & 38.20 & 17.50 \\
\hline 30.00 & 20.90 & 13.50 \\
\hline 28.50 & 16.90 & 16.55 \\
\hline 7.50 & 17.50 & 5.80 \\
\hline
\end{tabular}

Further the second methodology (hot DI+UV) is employed to bond cavity wafer and die shear test carried out at multiple locations of wafer as tabulated below in Table.6.
The results indicate weak bond strength in SOI wafer compared to standard wafer with the same recipe as SOI wafer. This needs higher potential and time due to embedded oxide layer. The same results are repeated for higher thickness glass wafer ( 40mils) indicating the repeatability of the proposed methodology. These results are outcome of the bonded device on 6" wafer for which wafer bow and warpage also plays an important role. The uniformity of bond strength can be achieved by reducing the size of the wafer, increasing the bond area and increasing the spacing between the dies.

\section{CONCLUSION}

The main challenge in micro-sensor devices with cavity and thin diaphragm is to achieve strong bond strength in spite of availability of lesser surface area. This article details the bonding process, role of various parameters, methodology for improving bond strength and characterization of the bond strength. As bond strength is dependent mainly on the temperature and voltage along with process methodology so this article deals with the latter aspect to achieve better bond quality. Simple cleaning methodology along with activation of the wafer surface thus making it hydrophilic without chemical treatment is presented. This approach results in better yield and cost effective compared to alternative techniques such as providing large bond area. Authors believe that proposed approach is easier implementable and can yield better results.

\section{REFERENCES}

[1] Kamaljeet Singh and A.V. Nirmal, "Reliability Aspects in RF-MEMS Circuits for Space Applications", Journal of Engineering and Technology Research, Vol. 4, No. 6, pp. 1$11,2016$.

[2] W.H. Ko, J.T. Suminto and G.J. Yeh, "Bonding Techniques for Microsensors", Proceedings of Conference on Micromachining and Micropackaging of Transducers, pp. 41-61, 1985

[3] Mohamed Gad-el-Hak, "The MEMS Handbook", $2^{\text {nd }}$ Edition, CRC Press, 2002.

[4] K. Petersen, P. Barth, J. Poydock, J. Brown, J. Mallon and J. Bryzek, "Silicon Fusion Bonding for Pressure Sensors", Proceedings of IEEE Solid State Sensor and Actuator Workshop, pp. 144-147, 1998.

[5] Hyun S. Kim, Robert H. Blick, D.M. Kim and C.B. Eom, "Bonding Silicon-on-Insulator to Glass Wafers for Integrated Bio-Electronic", Applied Physics Letters, Vol. 85, No. 12, pp. 2370-2373, 2004.

[6] R. Knechtel, G. Dahlmann and U. Schwarz, "Low and High Temperature Silicon Wafer Direct Bonding for Micromechanical Absolute Pressure Sensor", Proceedings Electromechanical Society, pp. 205-207, 2005.

[7] G. K. Ananthasuresh, K.J. Vinoy, S. Gopalakrishnan, K.N. Bhat and V.K. Aatre, "Micro and Smart Systems", Wiley, 2010. 